operations., Consultant for: The author has been provided with consulting fees from AbbVie Canada, Amgen Canada, Eli Lilly Canada, Pfizer/Hospira Canada, Pfizer Global, NovoNordisk, Janssen Canada and Global, Merck Canada, Novartis Canada., N. Robertson Grant/research support from: CAPA receives funding from a number of pharmaceutical companies to conduct its operations., L. Wilhelm Grant/research support from: CAPA receives funding from a number of pharmaceutical companies to conduct its operations., L. Proulx Grant/research support from: CAPA receives funding from a number of pharmaceutical companies to conduct its operations., A. McKinnon Grant/research support from: CAPA receives funding from a number of pharmaceutical companies to conduct its operations., J. Gunderson Grant/research support from: CAPA receives funding from a number of pharmaceutical companies to conduct its operations., C. Reece Grant/research support from: CAPA receives funding from a number of pharmaceutical companies to conduct its operations., A. Sirois Grant/research support from: CAPA receives funding from a number of pharmaceutical companies to conduct its operations.

DOI: 10.1136/annrheumdis-2018-eular.3955

\section{PARE0006 A SUMMARY OF KEY FINDINGS FROM THE SJÖGREN'S SYNDROME FOUNDATION'S NATIONAL PATIENT SURVEY RELATED TO TREATMENTS AND MEDICATIONS USED}

S. Taylor ${ }^{1}$, K.M. Hammitt ${ }^{2} .{ }^{1}$ Sjögren's Syndrome Foundation, Reston, VA; ${ }^{2}$ Sjögren's Syndrome Foundation, Reston, United States

Background: Sjögren's is a systemic autoimmune disease that affects the entire body. The purpose of this major national patient survey was to gain an understanding from adults who have been diagnosed with Sjögren's about the impact of the disease on their quality of life, including information on the treatments and medications used to manage the disease.

Methods: The Sjögren's Syndrome Foundation (SSF) conducted the Living with Sjögren's survey between May 11 and July 11, 2016. Participants were recruited by Harris Poll from a pool of 9,252 active SSF patient members. The survey was conducted among adults aged 18 years or older who reported having been clinically diagnosed with Sjögren's by a physician or other medical professional. The survey asked closed-ended questions about patient experiences with Sjögren's and the impact it has on their quality of life.

Results: There were 3,072 survey responses (33\% response rate), 2,963 of which were included in the analyses. Survey respondents were $96 \%$ female and $4 \%$ male; $32 \%$ were aged 60 years or less. On average, respondents reported using 8.8 medications and treatments to help manage their Sjogren's symptoms, with an average of more than four prescription medications and treatments. When comparing patients living with Sjogren's between 0-4 years and 5-9 years, respondents in the latter group reported using slightly more treatments, on average (8.7), compared to those living with Sjogren's for a shorter period (8.2 mean). Nearly all respondents (97\%) reported using eye drops, artificial tears, or non-prescription eye ointments. Other medications reportedly used by a majority of respondents include ibuprofen or other anti-inflammatory agents (81\%), disesase-modifying anti-rheumatic drugs (DMARDS) (67\%), over-the-counter or prescription fluoride (67\%), and corticosteroids (62\%). Notably, patients 60 years and younger were significantly more likely than patients older than 60 years to have used health food supplements or remedies ( $90 \%$ vs. $87 \%$ ), exercise ( $88 \%$ vs. $83 \%$ ), and alternative therapies (70\% vs. $58 \%$ ) in attempt to treat their Sjogren's. Nearly all respondents $(96 \%)$ indicated they wished that additional treatments for Sjogren's were available. Specifically, respondents indicated a need for new treatments for fatigue $(63 \%)$, brain fog/forgetfulness (53\%), sleep problems $(51 \%)$, joint pain or swelling (48\%) and muscle pain (43\%).

Conclusions: Patients reported relying on a large number and variety of treatments to manage their Sjogren's as well as the need for new treatment options to treat the various manifestations of the disease. The findings from this survey will help to inform and support future SSF efforts to increase public and professional awareness of Sjögren's and encourage research into new treatments and a cure. Disclosure of Interest: None declared

DOI: 10.1136/annrheumdis-2018-eular.5535

\section{PARE0007 FAMILY DAY BY THE SWISS LEAGUE AGAINST RHEUMATISM: A NETWORKING EVENT FOR CHILDREN AFFECTED BY JIA AND THEIR FAMILIES}

M. Roffler, V. Krafft. Swiss League Against Rheumatism, Zurich, Switzerland

Background: In Switzerland 0,7 out of 1'000 children is affected by juvenile idiopathic arthritis (JIA). The incidence of JIA is 11:100'000 (1). The families affected by JIA are spread over three different language regions (the German, French and Italian regions). It is difficult for these families to get in touch with other affected families since there is no support group for JIA. A support group has never been established due to the uneven distribution in Switzerland

Objectives: The aim is to offer continuing education for parents of affected children concerning their chronic disease, as well as their dealing with the illness as a family. Furthermore parents and children shall attain the opportunity to exchange information about their experiences and problems with peers in an informal setting.

Methods: The Swiss League Against Rheumatism has established the so-called "Family Day" (German: Familientag) which features a program for affected children/youths and their siblings as well as a separate program for their parents on the same day. In order to enable families from all Swiss language regions to participate in the "Family Day", it takes place separately in German and French in both language regions. Since most Italian speaking families in Switzerland either speak German or French, the "Family Day" is equally open to them. The Swiss League Against Rheumatism collaborates with the task group "Paediatric Rheumatology Switzerland" in order to develop relevant contents. The program for the parents aims at imparting medical therapeutic knowledge about their child's disease. Several additional main topics (e.g. uveitis, developmental paediatrics) are chosen and presented by certified experts. All are made in layman language and explain medical terms thoroughly. The parents additionally get the opportunity for formal and informal exchange within their group. The children and youth program (0-16 yrs.) is dedicated to a specific non-medical topic (e.g. magic tricks). The children are divided into several age-specific subgroups and are assisted by staff from the Swiss League Against Rheumatism. Teenagers (11-16 yrs.) may attend a specialized program during half a day

The "Family Days" are easily financed by foundation endowments.

Results: From 2011 to 2017329 families (1157 individuals) participated in the "Family Day", of which $27 \%$ were in the French-speaking part of Switzerland. For participating parents this event became essential in order to educate themselves concerning their child's disease and to exchange experiences with other affected families. For most families the "Family Day" has become a fixed event in their yearly calendar. Many families participate on a regular basis for several years. Conclusions: The "Family Day" has been taking place for 7 years and remains an objective for the future. Demand from parents of affected children continues to be strong and continues to increase. Since support groups have not yet been pos sible to implement due to demographics, this one-day-event remains a unique resource for affected families.

\section{REFERENCE:}

[1] Hofer M. Personal communication. Prof. Dr. med. January 30, 2018.

Disclosure of Interest: None declared DOI: 10.1136/annrheumdis-2018-eular.6323

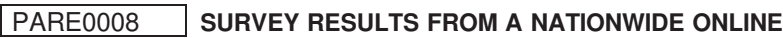 AWARENESS CAMPAIGN SUGGEST A CLEAR DIFFERENCE IN TREATMENT AND PERCEPTION OF QUALITY OF HEALTHCARE FOR PATIENTS DIAGNOSED WITH PSORIASIS ARTHRITIS, PSA, VERSUS PATIENTS WITH SYMPTOMS SIMILAR TO} PSORIASIS ARTHRITIS I.E. PSORIASIS AND JOINT PAIN

N. Unesi, E.-M. Dufva, L. Håkansson. Swedish Rheumatism Association, Stockholm, Sweden

Background: Psoriasis arthritis (PsA) is a chronic inflammatory joint disease closely linked to psoriasis in the skin. The need for increased knowledge of PsA is extensive in both the public and in healthcare in Sweden. For that reason Swedish Rheumatism Association, Swedish Psoriasis Association and health portal company NetDoktor, with support from Novartis, initiated a web-based awareness campaign, which included a survey, in April 2017.

On December 17, approximately 12,500 people, of which about 4,000 with the diagnosis PsA and 8,500 with psoriasis and joint pain, had taken part of the material. Of these, approximately 2,400 people participated fully and provided detailed information on how they view their disease and the care they are offered.

Objectives: Raise awareness and educate about to PsA aimed specifically to people with PsA or with symptoms consistent with the diagnosis - but also relatives, healthcare professionals and the interested public.

Methods: The awareness campaign consisted of five lessons that provided participants with increased knowledge about PsA, and a survey about their experience of healthcare. The survey gave us a foundation to address the deficiencies in healthcare, and in patient needs. The lessons highlighted the following issues: background, causes, symptoms, comorbidity, diagnostics, drug treatment and prognosis.

Results: The average waiting time for a diagnosis among the survey participants was 3,5 years. Every fourth person had waited 5 years or more, and over 10 percent waited more than 10 years for a diagnosis. The survey showed remarkable 
differences in life quality between people who have a diagnosis and people who do not have a PsA diagnosis or who have not yet received one:

\section{Many are without diagnosis and treatment}

High proportion of undiagnosed patients have symptoms indicating PsA. Many have suffered a long time from joint related pain and sought out treatment from a number of doctors.

3 out of 4 with joint pain have negative or very negative experiences of healthcare related to their joint pain. The survey participants indicated that they suffer from waiting a long time for healthcare.

\section{Major differences in perception of care and treatment}

Statistics on overall satisfaction with healthcare show remarkable differences that can be linked to getting a diagnosis. People with joint pain but without a PsA diagnosis indicate a great dissatisfaction with the care they receive. People who have been diagnosed with PsA are overall quite satisfied with the care and treatment they receive after getting a diagnosis.

\section{High use of opiate remedies for pain}

The use of pain reliever opiate drugs is remarkably high in the group with joint pain but without the diagnosis of PsA. Also very high use of non-steroidal anti-inflammatory drugs, NSAIDs.

Conclusions: Given that the prevalence for psoriasis arthritis in Sweden is between $10000-30000$ people, it is likely that the awareness campaign reached a considerable number of people with the diagnosis or with symptoms similar to it. The longer the patient goes without adequate healthcare the worse the disease gets. If untreated it could lead to permanent joint damage. Early diagnosis and treatment are important to slow down the disease.

References: www.HarDuPsoriasisartrit.se

Disclosure of Interest: None declared

DOI: $10.1136 /$ annrheumdis-2018-eular.4448

\section{PARE0009 CANADIAN ARTHRITIS PATIENT ALLIANCE: UNDERSTANDING MEMBER PROFILES AND NEEDS}

N. Robertson ${ }^{1}$, L. Wilhelm ${ }^{2}$, D.P. Richards ${ }^{3}$, L. Proulx ${ }^{4}$, A. McKinnon ${ }^{3}$, J. Gunderson ${ }^{5}$, C. Reece ${ }^{4}$, A. Sirois ${ }^{6} .{ }^{1}$ Canadian Arthritis Patient Alliance, Navan; ${ }^{2}$ Canadian Arthritis Patient Alliance, Midlands, King County; ${ }^{3}$ Canadian Arthritis Patient Alliance, Toronto; ${ }^{4}$ Canadian Arthritis Patient Alliance, Ottawa; ${ }^{5}$ Canadian Arthritis Patient Alliance, Glaslyn; ${ }^{6}$ Canadian Arthritis Patient Alliance, Montreal, Canada

Background: Established in 2002, the Canadian Arthritis Patient Alliance (CAPA) is a grass-roots, patient-driven, independent, national organization with members across Canada. CAPA believes the first expert on arthritis is the individual who has the disease. We assist members to become advocates not only for themselves but all people with arthritis. CAPA works with other organizations, representatives from all levels of government, and researchers to ensure the patient voice is both heard and present. We communicate the latest news on health policy developments, research, technology and emerging issues relevant to members through our newsletter, website, Facebook, Twitter and YouTube channels. CAPA welcomes all of those who support CAPA's goals, especially Canadians with arthritis, to become members.

Objectives: CAPA underwent a strategic renewal in 2013, re-establishing its focus and operations. Since that time, CAPA has produced an annual strategic plan, and reported on yearly achievements in relation to the plan. In 2017, CAPA decided to conduct a membership survey.

The survey was designed with three objectives in mind: (1) Understand our membership's profile and interests, (2) Understand member awareness and support for CAPA projects and strategic direction, and (3) Seek membership input on CAPA's website.

Methods: A survey was created using Survey Monkey (in both English and French, Canada's official languages) and sent to members. Results of the survey were sent to the members and made available on CAPA's website (http://www. arthritispatient.ca/files/5315/1128/7211/CAPA_Suvery_-_Spring_2017.pdf). As an additional incentive, two C $\$ 50$ VISA gift cards were drawn from among Canadian respondents. The survey was open from May 1 to 21, 2017.

Results: The response rate to the survey was $23 \%$ (that is, 85 respondents out of a possible 369). Of those who responded, the majority were women, with over $75 \%$ aged 55 years of age or over. Respondents came from all across Canada. Members generally came to CAPA to find information and stay abreast of events in the arthritis community; only a small portion, $17 \%$, joined to become more involved. Members supported CAPA's strategic direction, which aligned with their stated interests.

Members also provided feedback on the website. For the most part, members appreciated the information, providing some recommendations moving forward, including supporting a mobile friendly website (i.e., responsive design).

Conclusions: CAPA is using the information from this membership survey as confirmation of its strategic direction moving forward; continued focus will be on providing information, connecting with key stakeholders in the arthritis community (Canadian and abroad), and undertaking focused projects as they arise.
Member feedback has been critical in guiding the website redevelopment, which is currently underway. We expect it to be complete in early summer 2018.

Acknowledgements: CAPA would like to thank the organizations that collabo rate with us as well as various pharmaceutical companies whose funding enables our operation.

Disclosure of Interest: None declared

DOI: 10.1136/annrheumdis-2018-eular.3003

\section{PARE0010 NATURALLY HEALING THE CHRONIC PAIN AND HEALTH MAINTENANCE}

A. Phoka Charalambous. Cyprus League Against Rheumatism, Nicosia, Cyprus

Background: Everyday life is not easy for people with RMDs. Chronic Pain is the "roommate" usually on patient's life. Patients usually try to find other ways of confronting their symptoms, beyond drugs or other classic options such as physiotherapy. One of these ways that often people with RMD's are discussing is the treatment with Natural Healing Sources based on water which is used in various cultures from ancient times. Cyprus League Against Rheumatism gives these opportunities to the members every year; by organizing excursions in Natural healing resorts at least two times per year.

Objectives: The aim of organizing therapeutic trips to therapeutic treatment centers - Natural Healing Resorts, was to give members the opportunity to get acquainted with and experience this mode of therapy, with team approached on rehabilitation treatments, for patients who cannot afford to visit as individuals because of the cost or to travel as individuals tourists and they need extra services and attention. In addition to therapeutic qualities, it would also give psycho-social affiliation to people who would participate, which CYPLAR gives a lot of insight into all of its programs

Methods: In 2012 CYPLAR approach the Ayioi Anaryiroi Natural Healing Resort \& Spa which is situated in Miliou, a small village in Paphos area, and their thermal waters are from ancient times, organized the first trip to this healing Resort.

In 2014 CYPLAR approached a Cypriot travel agency, and asked for help to organize a trip in Sandanski, in Bulgaria, as after a research find that it is a very good and famous thermal water springs and not too far from Cyprus so was easy to access and not too expensive.

Results: The trip to Ayioi Anaryiroi Natural healing Resort \& Spa was very successful so every year at least one time is organized a trip for a weekend. The dif ference for the people with RMDs participated in this trip instead of going alone, is that CYPLAR is having better rates for members for this special weekend, and also the therapeutic treatments during this weekend are targeted on RMD's. Another ad is that people are coming close to each other, bonding, and sharing their experiences. Every time around 20 people with RMD's are participating on these trips. CYPLAR members have all year around discount. Future Goal is to be organized twice times per year.

The trip to Sandanski is organized every year in July ( 3 times until now).It is a ten days program and includes examination, target treatments based on each participant and his/her needs, also include sightseeing tours in the area, entertainment dinners, and many other amenities. It is a very succeed therapeutic excursion that 40 people are participating and has a lot of good results. CYPLAR conducted a survey among the participant of the last trip in July 2017 and the results are very encouragingly to continue and have these excursions for more and more years. At the question "Do you want to go again in Sandanski with Cyplar?" The answer was Yes for the $95 \%$ of the participants. Results showed also the need for people with RMDs to have this kind of therapies in their life and the beneficial effects on their health status.

Conclusions: Patients with RMD's need these types of therapy for their body health but also for their psychosocial improvement. CYPLAR will continue to sup port the members with these two excursions but also is trying to find new resorts to enrich the program and give more opportunities for members.

References: Survey - Participants Sandanski 2017 -CYPLAR

Disclosure of Interest: None declared

DOI: 10.1136/annrheumdis-2018-eular.2490

\section{PARE0011 FUNKA UTAN SKAM TO FUNCTION WITHOUT SHAME}

T. Diao. The Swdish Rheumatism Assocaiation, The Swedish Rheumatism Association, Stockholm, Sweden

Background: Introduction:

Kids, youngsters and adults with an immigrant background are more vulnerable in the new country of arrival. It is quite hard to learn a new language and the rules and regulation in the new country.

In several cultures, people with a visible or invisible disability can experience guilt and Shame because of their diagnoses. Due to the cultural background, most of the time the families are also feeling the same. This feeling could be conscious or unconscious due to the cultural background. 